San Jose State University

SJSU ScholarWorks

Master's Theses

Master's Theses and Graduate Research

1991

\title{
Instruction in the use of symbol shelves for students with profound disabilities
}

Emilie Gail Stewart

San Jose State University

Follow this and additional works at: https://scholarworks.sjsu.edu/etd_theses

\section{Recommended Citation}

Stewart, Emilie Gail, "Instruction in the use of symbol shelves for students with profound disabilities" (1991). Master's Theses. 266.

DOI: https://doi.org/10.31979/etd.hmsu-yh8v

https://scholarworks.sjsu.edu/etd_theses/266

This Thesis is brought to you for free and open access by the Master's Theses and Graduate Research at SJSU ScholarWorks. It has been accepted for inclusion in Master's Theses by an authorized administrator of SJSU ScholarWorks. For more information, please contact scholarworks@sjsu.edu. 


\section{INFORMATION TO USERS}

This manuscript has been reproduced from the microfilm master. UMI films the text directly from the original or copy submitted. Thus, some thesis and dissertation copies are in typewriter face, while others may be from any type of computer printer.

The quality of this reproduction is dependent upon the quality of the copy submitted. Broken or indistinct print, colored or poor quality illustrations and photographs, print bleedthrough, substandard margins, and improper alignment can adversely affect reproduction.

In the unlikely event that the author did not send UMI a complete manuscript and there are missing pages, these will be noted. Also, if unauthorized copyright material had to be removed, a note will indicate the deletion.

Oversize materials (e.g., maps, drawings, charts) are reproduced by sectioning the original, beginning at the upper left-hand corner and continuing from left to right in equal sections with small overlaps. Each original is also photographed in one exposure and is included in reduced form at the back of the book.

Photographs included in the original manuscript have been reproduced xerographically in this copy. Higher quality $6 "$ x 9 " black and white photographic prints are available for any photographs or illustrations appearing in this copy for an additional charge. Contact UMI directly to order.

\section{U.M.I}

University Microfilms International

A Bell \& Howeil Information Company

300 North Zeeb Road. Ann Arbor, MI 48106-1346 USA

313/761-4700 800:521-0600 


$$
\ldots \quad \ldots \ldots \ldots \ldots
$$


Order Number 1947181

Instruction in the use of symbol shelves for students with profound disabilities

Stewart, Emilie Gail, M.A.

San Jose State University, 1991

Copyright (C1992 by Stewart, Emilie Gail. All rights reserved.

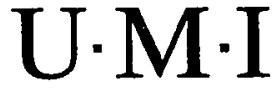

300 N. Zeeb Rd.

Ann Arbor, MI 48106 


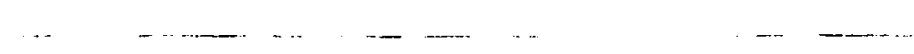




\title{
INSTRUCTION IN THE USE OF SYMBOL SHELVES FOR STUDENTS WITH PROFOUND DISABILITIES
}

\author{
A Thesis \\ Presented to \\ The Faculty of the Department of Special Education \\ San Jose State University
}

In Partial Fulfillment

of the Requirements for the Degree

Master of Arts

By

Emilie Gail stewart

December, 1991 
APPROVED FOR THE DEPARTMENT OF SPECIAL EDUCATION AND REHABILITATIVE SERVICES

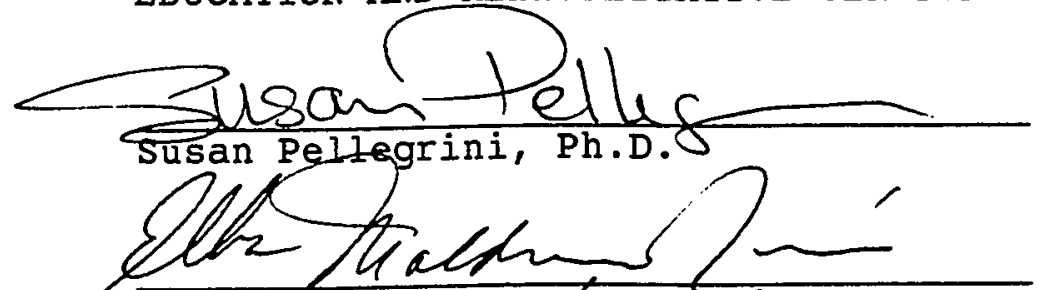
Elba Maldonado-Colon, Ed.D. Vevina ofearteca. Verjye Rarashian, M.A., C.C.C. APPROVED FOR THE UNIVERSITY Serena H. Etangore 


\begin{abstract}
INSTRUCTION IN THE USE OF SYMBOL SHELVES FOR
\end{abstract}

STUDENTS WITH PROFOUND DISABIIITIES

by Emilie Gail stewart

The research explored whether instruction in the use of symbol shelves enabled four pupils with profound disabilities to show growth in communicating wants and needs, both spontaneously and with teacher direction. A multiple baseline design across students' schedules was replicated four times. Each pupil's shelf contained four symbols corresponding to desirable items and activities in the school environment. Instruction involved teaching students to walk to their shelves, select a symbol, display it to an adult to communicate a want or need, and demonstrate comprehension of that symbol by walking to where the desirable activity took place.

The results showed that students developed improved spontaneous and teacher-directed communication after instruction in symbol shelf use. Staff felt the student gains were important and confirmed the relevance and appropriateness of symbol shelf instruction with this population. 


\section{ACKNOWLEDGMENTS}

I would like to acknowledge my parents Jim and Marcia Stewart who taught me the value of education. I would also like to thank my committee members for their kind assistance; Dr. Elba Maldonaldo, Verjene Kalashian, and especially Dr. Susan Pellegrini for all her constructive input. My appreciation goes to Michele white for the generous use of her computer and to Tom and Judy Jennings for their computer graphics expertise.

I would like to extend a special thanks to my assistant and friend Mary Jimenez who contributed so much extra time and energy during this research. My heartfelt gratitude also extends to my students who provided the inspiration for this study.

Most of all, my deepest appreciation goes to my husband Robert Mark White, who makes everything possible. 
TABLE OF CONTENTS

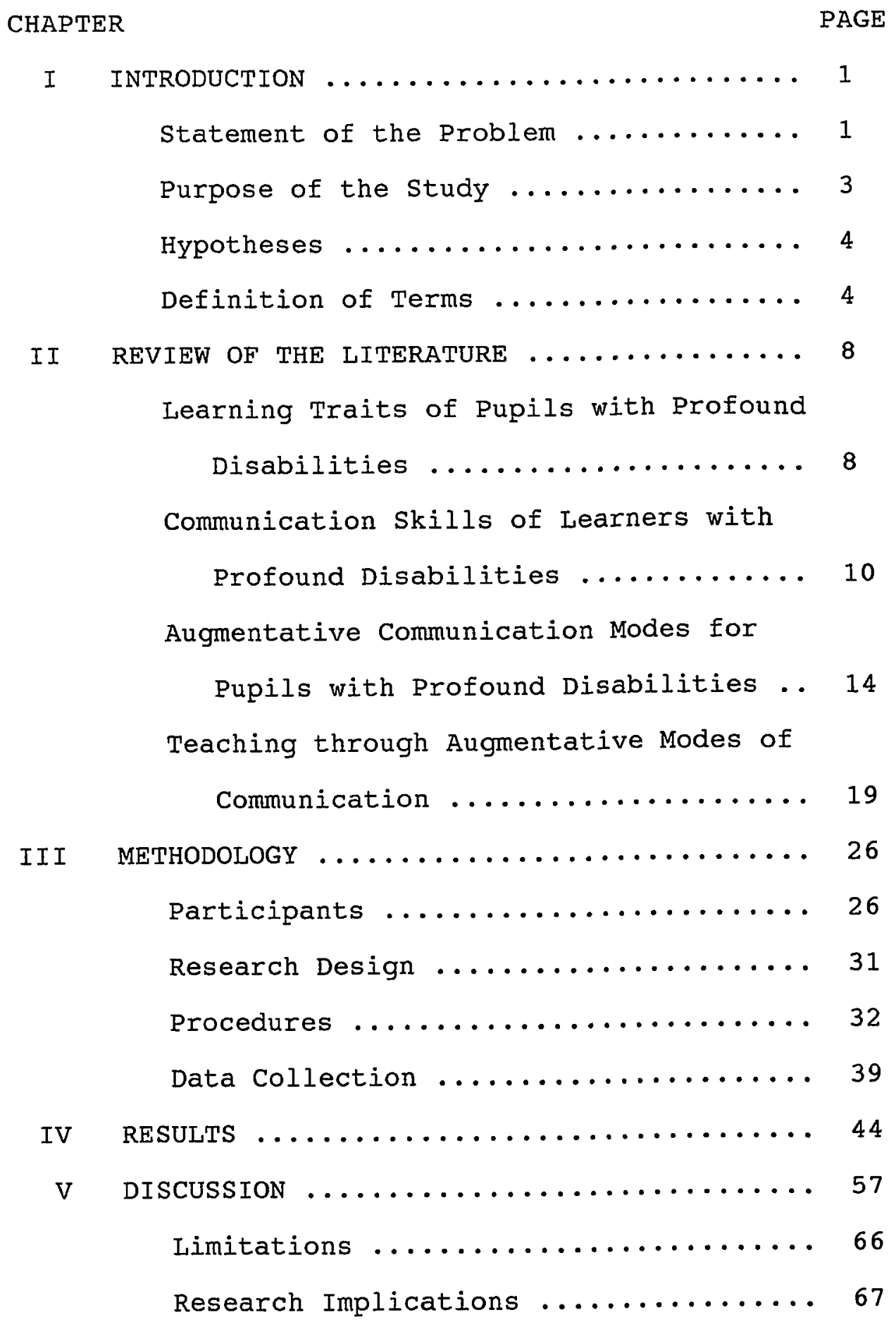


TABLE OF CONTENTS (Continued)

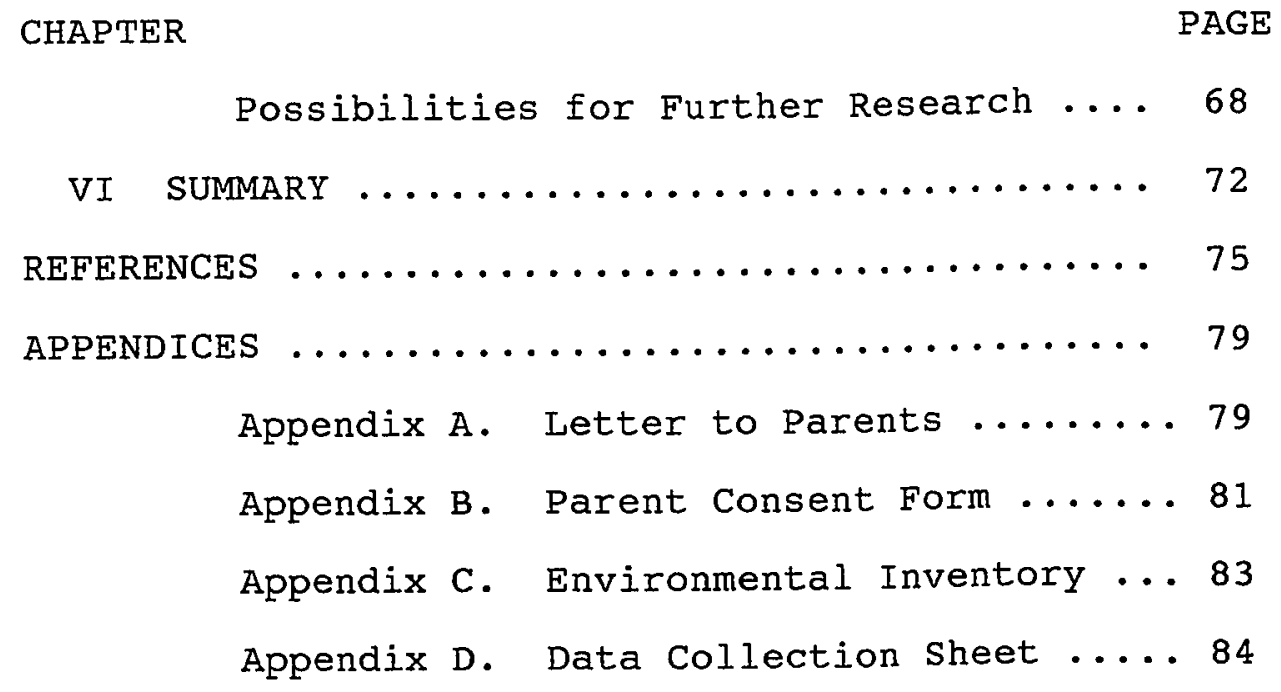

$v i$ 


\section{LIST OF FIGURES}

GRAPH PAGE

1. Lorenzo: Incidences of Communication ..... 47

2. Rudolfo: Incidences of Communication ..... 50

3. Javier: Incidences of Communication ...... 54

4. Inez: Incidences of Communication ...... 56

vii 


\section{CHAPTER ONE}

Introduction

Students with profound disabilities often lack basic communication skills. They may be nonverbal and not able to use or process sign language. Often the subtle types of nonverbal communication these pupils use are not perceived by those around them. Thus, like many behaviors that are not reinforced and shaped into more advanced skills, these communication attempts may be extinguished. Also, because profoundly disabled pupils need so much care and are often very slow at doing things of which they are capable, it is very easy to do everything for them and underestimate their potential. Therefore, students may not have any incentive to communicate, as most of their needs are met already (Downing \& Siegel-Causey, 1988). Since communication skills are so essential for a fulfilling existence, it is logical to conclude that the quality of life for most people without functional expressive language must be impaired.

\section{Statement of the Problem}

In order for pupils with few basic communication skills to come close to reaching their educational potential, they must be taught more effective communication strategies. The method of communication selected must correspond with students' current level of functioning and be intelligible to others. Not only will this require finding a functional 
communication strategy for each student, it will also necessitate structuring the initial stages of teaching, so students are taught to see the benefits of communication. Advantages for these pupils include obtaining what one wants, being part of pleasurable interactions, making choices and having a sense of control over one's environment (Siegel-Causey \& Guess, 1989). Ideally, a systematic communication intervention will not only help students communicate more efficiently, but also will transcend a narrow definition of communication and improve student functioning in other educational domains as well.

Teaching communication strategies to learners with profound disabilities is extremely challenging. In the past, students over six years of age have been assumed to be beyond the age when children can develop language. Historically, educators have focused on the idea that pupils must obtain certain cognitive prerequisites before language and speech therapy can be effective. This has occurred even though the connection between cognition and language is not easily understood and many of our assumptions about this linkage may not apply to students with profound impairments (Kangas \& Lloyd, 1988). Steps leading to full expressive communication include such components as initiating interactions, making choices and showing awareness of the connection between environmental cues and different events. 
These "substeps" are often missed by educators, even though they are critical to communication development.

Many students with profound disabilities will never develop functional speech. Therefore, instruction in augmentative communication methods is appropriate. Although the fields of adaptive technology and augmentative communication are continuing to develop, it is not easy to apply these new methods to pupils with profound disabilities. Research has shown that educators respond at extremely low rates to nonverbal indications of preference or choice making from students with severe disabilities, especially if the pupil is over five years of age (Houghton, Bronicki \& Guess, 1987). One suspects this finding would be even more prevalent for students with profound disabilities. Again, these subtle attempts at communication may then be extinguished because they are not reinforced.

\section{Purpose of the Study}

The purpose of this study was to teach students with profound disabilities ages 11 to 15 how to use a tangible symbol shelf as an aide to communication (Adam, 1985; Rowland, 1985; Siegal-Causey \& Guess, 1989; Silverrain, 1982). The focus of the investigation was to discover whether symbol shelves were functional communication systems for these pupils, enabling them to communicate more of their basic wants and needs, both spontaneously and with teacher 
assistance. This included exploring how to most effectively instruct and motivate pupils so they will communicate in ways that are clearly understood by those around them. If effective, symbol shelves should be a communication system that students can easily use both at home and at school to express their wants and needs.

Hypotheses

Hypothesis I: Systematic instruction in the use of a symbol shelf will enable pupils with profound disabilities to show growth in communicating basic wants and needs spontaneously.

Hypothesis II: Systematic instruction in the use of a symbol shelf will enable students with profound disabilities to show growth in communicating basic wants and needs in the presence of teacher-directed prompts. Definition of Terms

The following definitions were utilized in this study: Augmentative Communication: A communication system designed to provide an alternative or assisted means of expression for people for whom speech is not a functional communication option (Miller \& Allaire, 1987).

Communication: A social interaction that exchanges information, ideas, desires, requests, or questions. The transmission and reception of the message may use symbolic behaviors (e.g., spoken word, written word, sign language, 
Blissymbolics) or nonsymbolic behaviors (e.g., facial expression, body movement, touch, gesture) (Siegel-Causey \& Guess, 1989, p. 199).

Communication Board: Any type of flat surface on which written or drawn symbols are displayed so that the user may choose among them, using a predetermined method of responding in order to communicate a specific message (Miller \& Allaire 1987, p. 276).

Nonsymbolic: The use of gesture, facial expression, body movement, eye gaze, vocal sounds, and other expressions that are not part of symbolic communicative systems (Siegel-Causey \& Guess, 1989, p. 199).

Profound Handicaps: A student with profound handicaps is one who (1) is eligible to receive educational services under one or more legally defined categories of handicapping condition; (2) exhibits profound developmental discrepancies in all five of the following behavioral/content areas: motor/mobility, activities of daily living (self-help skills), communication, cognition, and social/emotional development; and (3) requires an educational structure with continuous monitoring and observation (Sternberg, 1988, p. 7)

Profound developmental discrepancy: One for which the individual's current performance level is no more than onefourth of the expectancy based on the individual's 
chronological age. However... if an individual is

functioning at or above a two-year developmental level in an area, the individual would not be considered to have a profound developmental discrepancy in that area regardless of chronological age (Sternberg, 1988, p. 7). Spontaneous communication: Expressive nonverbal communication through a variety of augmentative modes in the absence of teacher-directed prompts. Examples of spontaneous communication might include pointing to a picture of a cup to show that he/she wants a drink without teacher prompts and then drinking from a glass with obvious thirst.

Spontaneously-initiated communication: Expressive nonverbal communication through a variety of augmentative modes where the student initiates the interaction but needs some degree of adult prompting to make his/her meaning clear to others. An example of spontaneously-initiated communication might be when a pupil voluntarily brings his/her communication board over to an adult, but does not attempt to point to a picture and seems undirected on what $s /$ he had originally wanted. Tangible Symbol: Objects or pictures that bear a concrete relationship to the visual or tactile properties of the entities they represent (Rowland, 1990, p. 1). Teacher-directed communication: Expressive nonverbal communication through a variety of augmentative modes in the 
presence of teacher-directed prompts. An example of teacher-directed communication might be when, in order for commuication to occur, the instructor must place a communication board before the pupil and provide assistance for the student to use the board, in some or all of the subsequent steps of expressing a message. 
CHAPTER TWO

Review of the Literature

The following literature review includes a discussion of the learning traits of students with profound disabilities. Their receptive and expressive communication skills are presented. Different augmentative modes of communication available for these pupils will also be highlighted. Finally, techniques will be presented for teaching expressive communication through augmentative modes to students with profound handicaps.

Learning Traits of Pupils with Profound Disabilities

The learning characteristics of students with profound disabilities can be as varied as those of any other labeled "group" in the field of special education. When Thompson and Guess (1989) interviewed six instructors of pupils with profound, multiply handicapping conditions, the teachers described four characteristics of this population. These included "a limited level of awareness, limited response repertoires, no system of communication and medical complications" (p. 10). When discussing integration for these pupils, snell and Eichner (1989) noted slow learning rates, loss of skills from disuse and difficulty generalizing acquired skills to new environments, materials and other people.

Mulligan Ault (1988) states that the educational goals 
for profoundly disabled students should focus on increasing student awareness of the environment and developing a consistent response. Instruction should emphasize developing motor abilities, daily living skills, and increased social skills.

The following traits are characteristic of students with profound disabilities. These pupils need consistent instruction where tasks are broken into very small steps. Since generalization is quite difficult for this population, practice must be provided in a variety of environments with different people and different materials. The principle of partial participation is very important to consider when planning intervention. Partial participation involves teaching pupils to participate in an activity to whatever extent they are able rather than waiting for "prerequisite" skills to emerge. The instructor must view improvement in skill performance as a worthwhile objective, as well as working for total skill independence (which may not be feasible for many learners). Teachers should use very short phrases which correspond to students' receptive language abilities. Too often educators are excessively wordy with these pupils, who then are not able to process the verbal message presented. Educators need to express themselves at a level just slightly more advanced than the child's communicative level, so that $s /$ he understands what 
is said and is provided with appropriate models to enhance learning (MacDonald \& Gillette, 1986).

The more profound a student's developmental disability, the more difficult it will be to find appropriate reinforcers. Reinforcement needs to be built into the activity, if possible, so students will feel the rewards of learning. Researchers caution that once a student has satiated on edible reinforcers, responding and accuracy can diminish (Alberto \& Sharpton, 1988). Mirenda and Dattilo (1987) hypothesized that their failure to teach a student to use a communication board without prompts may have been because the subject became satiated on the activities and not motivated to continue performing. Therefore, the teacher needs to pair primary and secondary reinforcers as soon as possible and systematically reduce the amount of reinforcers provided the student (Alberto \& Sharpton, 1988). Communication Skills of Learners with Profound Disabilities

The communication skills of students with profound disabilities tend to be very limited. These pupils need to acquire "prelanguage" communication skills, before progressing on to more formal language systems. Many educators agree that attaining the sensorimotor cognitive stages correlates with success in communication development (Sternberg, 1988). Yet, this view is challenged by Kangas and Lloyd (1988) who note a lack of equality across 
cognitive areas for these learners. Cognitive measures are not as predictive of language development with disabled students as they are with nondisabled pupils. Kangas and Lloyd also state that there is very little data demonstrating a relationship between cognitive measures and communication skills for adults and teenagers with severe disabilities. They cite studies where augmentative methods were taught to severely disabled learners who later generalized these skills to different settings and tasks. The cognitive skills which correlated with learning symbols appeared to be different than those correlated with learning speech. Whether one subscribes to a strict cognition/communication correlation or not, methods of teaching augmentative communication are available and attainable for this population.

Sternberg and McNerney (1988) also note a correlation between social-interactive skills and communication development. MacDonald and Gillette (1986) support this view, emphasizing the importance of establishing social interactions with the disabled child. The educator needs to initiate and maintain regular interactions with a student, before the child can learn to communicate personal needs and imitate adult models. Some researchers also have found matching skills (either object-to-object and/or object-topicture) a necessary prerequisite ability before learners 
can benefit from augmentative communication instruction (Mirenda \& Dattilo, 1987).

Some degree of prompting is essential when teaching these students new communication skills. Mirenda and Datilio (1987) were not successful when attempting to teach three students with severe disabilities how to use a picture communication board without the benefit of outside prompts when initially learning the task.

Houghton, Bronicki and Guess (1987) found that students of different ages did not initiate expressions of preference or choice at significantly different rates in either structured or unstructured settings. However, this may have been due to a lack of staff responsiveness to students' communicative acts. It may not be indicative of how students of different ages will behave in an environment more conducive to communication. Most of the studentinitiated behavior consisted of body movements. Affective responses such as smiling and oral motor movements were the second largest categories. Verbal and other symbolic communication such as sign language were the categories least observed in student-initiated responses. In contrast to students' communicative behavior, adults used the verbal category most frequently. The adult behaviors were not congruent with the communication expressions used by the majority of the students in their study. This communication 
mismatch doesn't assist the student in learning the communication skills $\mathrm{s} /$ he so desperately needs. A lack of response to student communication attempts can inadvertently teach the learner that there are no rewards to be gained from attempting to communicate and promote added learned helplessness.

Further exacerbating the problem is the research finding that adults don't expect the child to stay in the conversation. Adults often communicate rhetorically with the student, using questions and commands which put the child in a passive role, rather than waiting for the child to exhibit a response (MacDonald \& Gillette, 1986).

Most learners with profound disabilities do not have functional speech and are not able to use sign language. Research has revealed several characteristics necessary for students to be favorable candidates for sign language instruction. Students should have good fine motor control and range of motion. They also need strong visual acuity and visual discrimination. Finally sensorimotor stage five or six is recommended (Molt \& Younginger, 1988). These characteristics are often beyond the abilities of students with profound disabilities.

While communication boards appear to be a possibility for these pupils, it becomes immediately apparent to the practitioner that an acceptable board for more advanced 
developmentally disabled pupils might not be appropriate for the student with profound disabilities. Iine drawings or small pictures may be too abstract for the student to understand the concepts represented. Even if large colored pictures or objects are used and the student acquires an understanding that an actual object or large colored photograph represents an object or activity, the student will still need to be taught that s/he can and should use the board to communicate a desire, need or choice to others.

Given that generalization is so difficult for this population, the teacher may experience frustration realizing that while the student may use the adapted board under teacher direction, s/he may not attempt to use it spontaneously. Similarly, while the student may use some type of communication at school, s/he may not attempt to use this skill at home. The necessity of not taking any aspect of communication for granted becomes immediately apparent when working with this population.

Augmentative Communication Modes for Pupils with Profound Disabilities

A review of the literature reveals that different augmentative communication systems are available and appropriate for nonverbal students with the most involved disabilities. Adam (1985) highlighted options for learners who are not at the symbolic level needed for sign language 
or picture boards. Some researchers have found three communicative phases which can lead to symbolic communication. These include the resonance phenomenon, the co-active movement and the non-representational reference phases. The resonance phenomenon involves doing a movement with the child that the adult knows the child likes. The learner and teacher are physically touching and moving together. The adult then stops and waits for the child to move his/her body in some way toward the adult, showing that s/he wants the movement to proceed. Co-active movement is defined as moving through space with the pupil. The learner and teacher still do the same movement at the same time, but are separated in space. If the teacher stops in the middle of the movement and the child continues, the adult knows that the learner remembers what comes next. During imitative movement, the student and teacher imitate each other. After the student has learned different movement signals, s/he then may progress to acquiring more conventional gestures. In the nonrepresentational reference phase, the child is beginning to understand symbols. When the learner sees that one thing can represent another, more abstract types of representation can be taught (Adam, 1985; Kangas \& Lloyd, 1988).

Bryen, Goldman, and Quinlisk-Gill (1988) examined the use of sign language with students who had previously 
been labeled as having severe and profound disabilities. They discovered that many of the reasons cited by speech/language clinicians as to why they chose sign language as an augmentative communication system for these pupils (e.g., students' ability to imitate and wanting to use a total communication approach) did not correspond with a scientifically validated rationale for selecting sign language (e.g., have the cognitive and motor prerequisites and building on existing gestures). The Individualized Education Program (IEP) goals for these pupils were expressive ones, which also conflicts with child development research which indicates that receptive input is a necessary prerequisite to expressive output. Thus, while the authors found the typical pupil in the study spontaneously used only four signs after an average of three years of instruction, the researchers were uncertain whether the students' difficulties in learning signs were because they had not been taught correctly or whether sign language in itself is not the best communication method for these pupils. Many choices are available for the practitioner interested in designing either object or a picture communication systems for learners with disabilities. One option is to teach students to indicate they want a desired item from an array of two or more choices as a preliminary step before developing an object communication board. The 
learner is first taught to signal that $s /$ he wants one desirable item with no other choices. The student then progresses to choosing from two possible alternatives (Kangas \& Lloyd, 1988).

Another option is to create picture communication boards from "scratch" using magazine cutouts, catalog pictures, food labels, photographs or colored line drawings. Portable systems can be designed by combining pictures in books or on flip charts attached to belts or shoulder straps. For students with few scanning skills, a basic one picture per page system might be most appropriate. Pictures can be mounted on dark or light backgrounds. Pupils with short visual attention may need colorful, large pictures and upright table stands for their communication books. For those who have difficulty crossing their midline, pictures can be grouped from top to bottom on one side of each page. Pages are then bound together so they can be turned in the opposite direction of the dominant hand.

Pictures can be grouped in categories or by environment so that the book has a school pictures section and a home pictures section. The book can contain photographs of different nouns and verbs, so that more advanced pupils can communicate a variety of short phrases. When teaching the use of a pictorial communication board, instructional strategies should include the use of motivating pictures 
initially, followed by more practical vocabulary once the student begins to use the system spontaneously (Mirenda, $1985)$.

Wacker, Wiggins, Fowler, and Berg (1988) taught nonambulatory students with profound disabilities to make choices and ask for desired items via microswitches. Initially, students were taught to activate adapted toys with microswitches. Through a series of small experiments, they then progressed to the point where they could activated taped messages to tell their teacher that they wanted a drink and then order that drink in a fast food restaurant.

Rowland (1985) believes tangible symbol systems can provide a link from presymbolic to formal symbolic communication. Tangible symbol systems use objects as a permanent representation of objects or events in the environment. Possible advantages of tangible symbol systems include: 1) they require only recognition memory, rather than recall memory for communication, 2) they usually resemble their referent, and 3 ) they are easy to discriminate. Candidates for concrete symbol systems are pupils who have a few gestures, such as pointing, extending objects, tapping people for attention, etc., but who don't have speech, sign or the representational skills required for picture communication. Concrete symbols may enable the learner to communicate about specific stimuli in the 
environment when other methods have not been successful. Teaching through Augmentative Modes of Communication

A variety of techniques are available for teaching expressive communication through augmentative modes. Alwell, Hunt, Goetz, and Sailor (1989) outlined a method for using interrupted chaining to teach generalized communicative behaviors. Students were each taught a different method for requesting an object, event or assistance to reinstate an activity. One student was taught to use Signing Exact English (SEE) signs, the second a card with the word "want" written on it, and the third a picture communication board. Students were assisted in a routine to a predetermined interruption point (e.g., toy moved out of child's reach). After waiting five seconds, if the pupils exhibited the targeted response, they were reinforced and given what they requested. If not, the adult modeled the correct response and guided the student through it. The instructor then waited ten seconds for the pupil to try and reinstate the activity. If the child performed correctly, s/he was reinforced and given what s/he wanted. If not, the item was removed and the student was not allowed to complete the routine at that time. All pupils showed a steady increase in their individual targeted behaviors and reached set criterion quickly. In addition, they generalized their communicative behaviors to different situations in $100 \%$ of 
the probes.

Sternberg, McNerney, and Pegnatore (1987) combined use of both the resonance phenomenon and the co-active movement phase in a manner similar to the methods described earlier by Adam (1985). They taught students with profound disabilities to grasp the experimenter's finger to show that they wanted a co-active movement. The experimenter modeled the co-active movement and paused. If the student exhibited the taught signal, the researcher immediately produced the co-active movement for five seconds. If no signal was produced, the experimenter modeled the signal, produced the movements for five seconds and then paused once again for the signal. All subjects reached criterion for change and appeared to generalize these behaviors to other adults. However, the experimenters did note that they could not state this conclusively, as they had not provided baseline data for the other persons. They also did not provide data to show that maintenance occurred.

Kangas and Lloyd (1988) also highlighted teaching the use of a signal to represent "more" and some generalized symbol to represent "want." An important element in teaching choice behavior is teaching the student how to indicate protest or rejection. Physical assistance may be provided to teach students to push away unwanted items. Downing and Siegal-Causey (1988) outlined general 
instructional procedures to increase the nonsymbolic communication skills of children with severe and profound disabilities. Communication training should occur within useful activities as the need to communicate naturally arises. The teacher should provide the student with increased sensory input to help the student understand better what is occurring in the immediate environment. Responding to student's nonsymbolic actions will teach the child that these behaviors can be used to communicate. This is critical since the ability to get another person's attention is necessary for further communicative interactions. The student should be given choices during daily routines to develop motivation for communication. Group instruction can promote natural social interaction. A systematic delay procedure, like the interrupted chaining method explored by Alwell et al. (1989), can give the child enough time to start an interaction or react to a direction. A consistent classroom schedule also promotes communication. Any behavior the student displays related to the schedule can be shaped into a communicative act. Finally, instruction should include a systematic method of cueing, prompting, fading assistance and providing reinforcement and feedback.

MacDonald and Gillette (1986) found that before a child learns to communicate, s/he must see the rewards of back and 
forth turn taking. The educator needs to teach the child to know when to act, then wait for another's turn, then act again meaningfully. This is facilitated by playing in routines with the child where the turn taking aspect of the interaction is emphasized. A significant principle that keeps reappearing in the literature is the importance of acting once, then waiting silently for the child to respond. Throughout the interaction the instructor should keep the child communicating by responding with a cue for more. The practitioner should describe the child's current experience, giving words for his nonverbal communication.

An anticipation or symbol shelf (Silverrain, 1982) can also be used to teach students with profound disabilities to communicate. The first step for the teacher interested in developing a symbol shelf is to discover the child's favorite activities. The adult fits these tasks into a daily classroom routine. The next step is to choose objects to act as symbols that can be incorporated into these activities. The teacher picks objects that are actually used in these activities. For example, a spoon might represent lunch, a ball could stand for recess, and a box of crayons could signify art activities. The objects are placed in sequence on a shelf that the child can reach. Every day, the adult motors the child through getting each object off the symbol shelf and taking it to the 
corresponding activity at the correct time. According to Silverrain, if after six months the child is not showing any signs of anticipation in the day's routine, the shelf can be discontinued. The ultimate goal is for the child to express him/herself symbolically using the objects. Eventually the child should begin to spontaneously walk to the shelf and pick up objects or bring them to an adult. When the child initiates this type of communication, the teacher needs to comply with the child's request. Later, the pupil can be taught that $s /$ he may need to wait for this activity. Silverrain states that after using the shelf, it is easier to make a transition to other forms of communication.

Rowland (1985) also provided useful guidelines for the practitioner considering the use of symbol shelves. When first introducing symbols, choose a functional referent for which many opportunities for practice will take place. That way the student will receive enough training to make the association between the symbol and the referent. When beginning the program, the student may need to start with only one symbol. However, until the learner discriminates between two or more symbols, one can not be certain that the student is associating one symbol solely with one referent. Once the student is correctly using two symbols, increase the number of symbols used on the shelf, thereby increasing the size of the student's vocabulary. Finally, the more 
perceptually related a symbol is to its referent, the easier the symbol may be learned. As the student progresses, the symbols may become increasingly more abstract.

Rowland (1985) states that when considering the use of symbol systems, target students must have presymbolic intentional communication. Most students will begin with concrete objects. However, a pupil with picture-object matching skills may begin directly with concrete pictures. The ultimate goal is for students to move to abstract objects and abstract pictures. However, individual differences will obviously be taken into account when designing and modifying programs for learners with profound disabilities.

\section{Summary}

Students with profound disabilities can be characterized by their great difficulty in learning across all curricular areas. They need highly specialized teaching techniques in order to be successful in meeting their educational goals. Developing functional communication skills is especially difficult for these pupils. They do not usually learn to express basic wants and needs through traditional methods. Given the importance of communication in all educational areas, the need for augmentative methods of communication is readily apparent.

One method for teaching these pupils is through the use 
of symbol shelves. The concreteness of the symbols helps promote student awareness that each symbol stands for one specific referent. When students are associating different cues with predictable events in their environment, receptive skills necessary for expressive communication are being formed. Optimally, symbol shelves will promote initiation and making choices, necessary for true intentional communication. Another benefit is that students can access the symbols independently in the classroom, thereby fostering more spontaneous communication. The purpose of this study is to explore whether symbol shelves are an effective method for promoting both spontaneous and teacherdirected communication in students with profound disabilities. 
CHAPTER THREE

Methodology

The following research examined whether instruction in the use of symbol shelves led to increased spontaneous and teacher-directed communication in learners with profound disabilities.

\section{Participants}

Four students with profound disabilities enrolled in a rural special day class participated in the intervention. The subjects' ages ranged from 11 to 15 years. All the participants were Hispanic.

These four students were selected from a class of eight pupils by the classroom teacher. They had the mobility skills necessary to independently access their own symbol shelf and the fine motor skills to select a specific symbol from a set symbol array. In addition, they met Rowland's (1985) criteria of student characteristics that indicate a need for a concrete symbol system. Candidates are students who are nonverbal and not able to use sign language. Rowland stated that students should have some gestures and presymbolic intentional communication. Three of the students were essentially nonverbal and two of these three occasionally used a few very rudimentary gestures to communicate. While the third nonverbal student did not use intentional gestures, he communicated a variety of messages 
through body language (walked briskly toward favored adults and cooed happily when he saw them, turned his head and looked away when he did not want to do something). The fourth student used some simple signs and spoken words (a set group of one word utterances) in a limited manner with prompting. However, his expressive communication abilities were not sufficient to express his wants and needs. As a result, he often exhibited negative behavior when apparently frustrated at an inability to communicate. Students sometimes touched enlarged photographs to communicate simple needs under very structured situations. However, this appeared to be more of a function of repeated practice and some understanding that the adults wanted them to perform this task. Students didn't evidence a true understanding that pictures can symbolize many things and that one can spontaneously touch pictures to communicate different messages to others in order to have more control over one's own environment. The following is a detailed description of the four participants.

Lorenzo: Age 14.4

Lorenzo has been described in the past as having Prader-Willi Syndrome and a profound developmental disability. He receives medication at home for his mild seizure disorder. He lives at home with his parents and five other family members. Both English and Spanish are 
spoken in his home. Lorenzo has participated in special education since the age of three. He was a student in a county development center for two years before being placed in his current class for children with severe/profound disabilities eight years ago.

Lorenzo is nonverbal and does not vocalize, except for very occasionally producing vowel sounds. Lorenzo coos when excited and laughs easily. He will touch pictures upon request, but in an indiscriminate and nonspontaneous manner. They do not appear to be a communication system option for him at present. His fine motor skills are quite limited and sign language instruction is not a realistic communication alternative. Lorenzo follows directions well and evidences more receptive language understanding than his expressive skills would suggest.

Rudolfo: Age 12.10

Rudolfo has a severe seizure disorder only partially controlled by medication, concurrent with his profound developmental disability. His ability to follow different directions seems to vary according to his present incidence of seizures and medication levels. He lives at home with his parents and two siblings. His mother reports that, while the adults talk to each other in Spanish, both Spanish and English are spoken in the home. Rudolfo participated in two infant stimulation programs beginning at three years of 
age. He has been a student in his present class for pupils with severe/profound disabilities for eight years. Rudolfo is nonverbal and rarely vocalizes. Prior to the beginning of the intervention, he used some rudimentary gestures to communicate spontaneously (e.g., hugged adults to indicate affection, sometimes handed a cup to an adult to show he wanted something to drink). With prompting, Rudolfo would occasionally take an adult's hand to a desired object to show that he wanted that item. Rudolfo matched a set group of objects to corresponding enlarged pictures. Upon first glance, it appeared that he would touch pictures upon request to indicate what he wanted out of two choices in very structured situations. However, upon closer examination, it became apparent that Rudolfo would often touch one picture when he really wanted the item represented by the other (e.g., would touch "milk" picture and then try to grab his full lunch plate). He did not spontaneously touch pictures to indicate wants and needs.

\section{Javier: 14.10}

Javier's initial school psychological evaluation for his current placement described him as having a profound developmental disability. Javier has a thyroid disorder which appears to affect his behavior. He receives medication for his condition at school during the week and at home on the weekends. Javier lives at home with his 
parents and six of his eight siblings. While spanish is emphasized in the home, family members speak both Spanish and English. Javier has been in his present placement for seven years. Prior to that, he was enrolled in two special education programs in southern California for a short period of time.

Javier follows directions well and can do a variety of very simple tasks around the classroom. He uses both Spanish and English words. Javier will attempt to repeat words and signs with the teacher and seems interested in the process. He can identify a variety of simple pictures. When the study was initiated, he used some one word utterances to communicate wants and needs (e.g., "agua, milk, outside, jump") and was occasionally able to combine one sign with one word to extend his meanings (e.g., signed "go" and said "outside" for "go outside"). However, Javier's communication abilities were very inadequate for his needs and, as mentioned previously, he often appeared frustrated and seemed to exhibit negative behavior when he couldn't communicate to others.

Inez: Age 11.0

Inez has an immune deficiency which has caused her health to be frail and her school attendance poor. Inez lives at home with her parents, four siblings, one niece and one nephew. Her parents speak Spanish to each other. 
However, they report using both Spanish and English to talk to Inez.

Inez's most recent psychological evaluation noted that she demonstrated significantly below average general intellectual functioning along with deficits in adaptive behavior. While never specifically labeled as "profoundly disabled," she was moved to her current placement for older learners with profound disabilities because she was not making progress in a primary classroom for severely disabled students. She had been in a class for severely delayed pupils from 1985 until the spring of 1990 when she was reassigned to her present placement. Prior to entering school at age six, she received some private speech therapy every other week for a few months.

Inez displays some limited verbalizations, repeating set phrases such as "right there," "bye" and "Mommy." However, she does not appear to use these words as an obvious method of communication. She evidences understanding of different directions. When the study began, Inez used a few gestures including pointing to desired objects. However, they were not enough to compose an adequate communication system for her.

\section{Research Design}

A quasi-experimental multiple baseline research design across students' schedules was replicated four times. This 
design was chosen as it was appropriate for this population's diversity and was easily adapted to a classroom teaching situation.

\section{Procedures}

Assessment: Before beginning this study, the teacher, the parents of selected students and the language and speech therapist met together. The purpose of this meeting was to select appropriate symbols and activities to include in the study for each student. After explaining the study to the parents and discussing the informational parent letter (see Appendix A), parents gave permission for their children to participate in the study (see Appendix B). At this meeting, parents assisted the teacher in filling out Carlson's (1981) environmental inventory (see Appendix C). The inventory was used to highlight motivating activities and practical vocabulary for pupils who were nonverbal. An attempt was made to pick activities/items that were highly reinforcing to the students, functional and not disruptive to the existing classroom schedule (e.g., a symbol for "bus" was not chosen, even though it might have been motivating for the students and was functional, because it would not have feasible for the pupils to go home whenever they chose). When possible, some items were selected that could also be used at home, so interested parents might be able, at a later date, to use these same items at home to promote 
generalization and functionality. Parents were asked if they were interested in receiving some training on how to implement similar procedures at home after the conclusion of the study.

Symbols representing the referents food and drink were selected for every pupil because they all showed interest in eating and drinking. In addition, symbols were chosen to represent outside for all the participants because they either obviously enjoyed going outside or had appeared to in the past. While each student had a leisure symbol, the particular symbol and its accompanying referent varied according to individual student interest. The attempt was to select referents that students found so reinforcing they would communicate that they wanted these items. This selection occurred even if the items were not necessarily what the teacher would have chosen as ideal leisure activity materials.

Since Javier verbally labeled familiar pictures and understood the concept that one could communicate by touching a picture, his symbols were pictures. The other students had objects as their symbols. The following is a list of each students' symbols and corresponding referents:

Lorenzo: toy truck (representing different battery operated toy vehicles he would activate using an adaptive switch), hip bag (representing recess and trips in the 
community), plate (symbolizing food), cup (symbolizing drink).

Rudolfo: block (representing different manipulative toys he would sometimes play with spontaneously), hip bag (see above), plate (see above), cup (see above). Javier: leisure activity picture (including the referents puzzle, art activity and legos), outside picture (representing recess and trips in the community), food picture and drink picture.

Inez: little book (representing books she enjoyed), hip bag (symbolizing recess and trips in the community), plate (representing food) and cup (representing drink).

Baseline: The frequency of students' baseline nonverbal communication was tabulated. Both spontaneous and teacher-directed communication were measured by videotaping each pupil for ten minutes daily in a targeted activity before the intervention actually took place. Both the teacher and another observer watched these videotapes at a later time and recorded any incidence of spontaneous communication and communication after the presentation of a teacher-directed cue. Staff continued to gather baseline data until a stable trend was indicated. While this varied with different pupils, data was collected for approximately three days.

Intervention: The teacher provided the initial 
individualized direct instruction in expressive communication using the symbol shelf designed for each pupil. After observing the teacher, the instructional assistant presented the intervention to students on a rotating schedule with the teacher. Students were taught to perform each of the following four steps integral to using the symbol shelf.

First, students were instructed to access their shelf. The teacher provided them with a verbal cue and a directive gesture to walk to their shelf (e.g., Teacher said, "Time to show me what you want. Go to J's shelf!" and pointed to student's shelf). If the student did not respond, more directive prompting was provided. However, lower degrees of prompting were attempted first in order to maximize students' independent functioning. Optimally, less assistance was needed as the study progressed. The degree of prompting initially used was specified on the student's data collection sheet (see Appendix D). As less assistance was needed, these changes were reflected on later data pages.

Second, once the student was facing his/her symbol shelf, the teacher provided instruction on how to select a symbol. She said something like "What do you want?" and pointed to the first symbol available on the left hand side of the shelf. Optimally, the student picked up or pointed 
to the symbol. However, if $\mathrm{s} /$ he did not, more assistance was provided (e.g., the teacher might model the appropriate response or touch the student's hand and lead it in the direction of the symbol). Again, the amount of assistance needed varied with each pupil.

The third step called for the student to display the symbol to the teacher. The teacher held out her hand for the symbol and said something similar to "Show Gail. Show Gail what you want." The learner was to then give the symbol to the teacher. If $s /$ he did not, assistance was provided as noted above. The teacher gave the student feedback on the appropriateness of his/her performance and on what the item $s /$ he has chosen represented (e.g., "Yes, outside! You showed Gail ball for outside! Good job J.!"). This feedback was very important, as the display step was where real expressive communication occurred.

The final targeted step was for the student to show that $s /$ he comprehended what the symbol meant (and was not just picking it because it was the next one on the shelf) by going to the area where the activity took place. The teacher provided the verbal cue and a pointing gesture to initially teach the student what each object represented (e.g., teacher said "Ball is for outside. Go to outside door" and pointed to the appropriate door). The student was supposed to walk independently to the designated area. If 
s/he did not, additional help was provided and noted on the data collection chart. Students were taught to take the designated item to the appropriate area where the activity took place, reinforcing the connection that each object represented a particular activity. They set each object down at that activity site. The adult later put the item back on the symbol shelf so that the student could subsequently access the symbol independently and spontaneously communicate.

Initial instruction was for approximately ten minutes a day. A second practice training session may have occurred each day, but was not required. In the beginning, the intervention was applied to one segment of each pupil's schedule (e.g., lunch). The section chosen varied according to each pupil's interest, with the intent being to select an area of high interest and motivation for each learner. Once pupils had shown at least one incidence of spontaneous or teacher-directed nonverbal communication in the selected context, the intervention was then applied to another part of each student's schedule (e.g., recess). Possibly a part chosen was less obviously intrinsically motivating for the student than a previous area. However, it was still an area of student interest. The intent was to gradually increase students' communication skills in a variety of contexts. In sum, the intervention was applied to four sections of each 
student's daily schedule for a total of approximately 40 minutes per day. The same criteria were used for advancing to each new area (at least one instance of spontaneous or teacher-directed communication by the student).

The ultimate goal of this study was for students' to begin expressing themselves spontaneously via the symbol shelf. If a pupil independently initiated going over to his/her symbol shelf at times other than the four sessions prescribed for teaching initial shelf use, the teacher or the assistant stopped what she was doing and responded to the student. This responsiveness was critical in order to reinforce any student attempt at spontaneous communication. If the student spontaneously performed all four steps involved in expressive communication, all the adult needed to do was respond enthusiastically to the student's message and record the data. However, if the student voluntarily initiated the interaction, but needed help on some of or all of the remaining communicative steps, the staff member provided direct instruction in the manner previously outlined. The adult used the minimal number of prompts possible, while still providing the learner with the assistance needed to continue the interaction and see the rewards of communication. During the course of the study, the attempt was to always respond to the student's message even if not convenient (e.g., the adult gave the student 
food if that was what $s /$ he had requested even if $s /$ he had been eating steadily all morning).

Results were analyzed to determine if the intervention did indeed cause the development or increase of teacherdirected and spontaneous communication. If the intervention was judged successful, it was explained to the parents to encourage them to implement the plan at home as well.

\section{Data Collection}

Instrumentation: The data collection form used in the study was derived from the instrumentation developed by Rowland and Schweigert (1990). Changes included eliminating some steps Rowland and schweigert had included as part of a communicative interaction. This researcher wanted to highlight the most critical part of a communicative exchange, feeling it was important to structure for success with pupils who were not proficient communicators. The definitions of spontaneous, spontaneously-initiated, teacher-directed and "non-responsive" communication and the corresponding level of prompts that determined the pupils' "score" in the above categories were developed for this study by this researcher.

Data Collection Training: Before the study began, the behavior of students not included in the study was videotaped. Ten minutes of behavior, four times a day were filmed for different students. Pupils were videotaped doing 
tasks similar to those that were targeted in the study. Afterwards, the teacher and the instructional assistant independently analyzed student behavior. The assistant was taught how to record data on student performance. The teacher explained how to measure the target communication skills and how to record them on data sheets. When the teacher and the assistant reached $90 \%$ agreement on the incidence of both teacher-directed and spontaneous communication, baseline data collection with the participant students began.

Data Collection Procedures: When analyzing the steps involved in expressively communicating via a symbol shelf, it became clear that there are many intermediate levels of communication between totally spontaneous expressions and those requiring prompting throughout the entire sequence. While recognizing the many subtle levels that show improvement in communication, it was decided to break these steps into four categories. A communicative act was considered totally spontaneous if the student performed all of the communicative steps outlined for each interaction without teacher cues. S/he needed to: 1) access the symbol display, (walk over to the shelf), 2) select a symbol, 3) display it to an adult (either by pointing to it or handing it to an adult), and 4) show that $s /$ he comprehended the symbol s/he has chosen by then going to the activity, 
object, area of the room, etc. that was represented by the symbol. In contrast, a communicative expression was considered spontaneously-initiated if the learner independently accessed the symbol shelf, but needed assistance with some or all of the remaining steps (selecting a symbol, displaying it to an adult and demonstrating comprehension). Teacher-directed communication occurred if the student required teacher cues (physical, verbal, modeling, etc.) to access the shelf and possibly to perform one, two or three of the remaining steps in the communicative process (see above), but performed or participated in the performance of each step when provided with the designated cues. A "no response" was coded if the student required full physical prompting and assistance to perform each of the four designated steps of communication (access, select, display and comprehend) and did not demonstrate any active participation in this process. Whenever students either A) exhibited totally spontaneous communication, or B) showed spontaneouslyinitiated communication, staff responded as previously outlined. In addition, staff took data on both types of communicative attempts. The teacher or the assistant used the same data collection chart employed for teaching symbol shelf use during each student's four scheduled data collection periods. They noted that the student accessed 
the symbol shelf independently without adult cues and then specified what degree of adult assistance (if any) was needed for the student to continue and complete the communicative interaction.

The frequency of teacher-directed, spontaneouslyinitiated and totally spontaneous expressive communication was calculated. Data was collected for the entire day every day for each participant for ten weeks. The teacher and the assistant rotated their schedule as needed so that both were charting all the students on all the activities.

Reliability checks were conducted three times during the intervention. The students were videotaped for reliability checks during set teaching times. The teacher and the instructional assistant later observed each target student together on the videotapes. They compared their findings. Reliability was calculated according to the following formula:

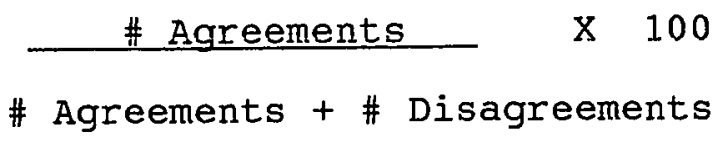

The teacher and the instructional assistant were in $100 \%$ agreement on how to score student performance for these reliability checks.

Data Analysis: A verbal description of the graphed results was presented regarding whether changes in the amount of both teacher-directed and spontaneous 
communication did occur. The results and their implications were summarized, tentative conclusions were drawn and suggestions for further research were discussed. 


\section{CHAPTER FOUR}

Results

The purpose of this study was to determine if instruction in the use of tangible symbol shelves would improve both the spontaneous and the teacher-directed expressive communication skills of students with profound disabilities. Instances of spontaneous communication were further divided into those that were totally independent and those that were spontaneously initiated by the student, but required some degree of adult assistance in the subsequent steps of relaying a message. Students were taught to walk to their individual symbol shelves. They were then instructed to select a symbol from the shelf and display it to an adult. Finally, they were to demonstrate comprehension of what they had just chosen, by walking to the area where the activity represented by that symbol usually took place. Data was recorded on pupil performance during teaching sessions. In addition, whenever students spontaneously initiated communication by walking over to their shelves independently, adults enthusiastically responded to students' communication and recorded data on their performance. Data collected included whether students communicated with total independence or whether they needed some adult assistance in the successive communication steps as outlined above. 


\section{Lorenzo}

During the course of the study, Lorenzo was in attendance for 40 out of a possible 51 intervention sessions. While baseline data was only collected for three days, this was enough to indicate a stable trend. It is notable that Lorenzo did not communicate with total spontaneity or spontaneously initiate communication once during baseline. While one could not say with certainty that he never communicated in this manner before the intervention, classroom staff did feel that his baseline performance was indicative of his general communication skills prior to the initiation of the study. Once the intervention began, Iorenzo communicated with total spontaneity six times and spontaneously initiated communication 24 times over the 10 weeks (see figure 4.1 ).

Lorenzo communicated with total spontaneity once and spontaneously-initiated communication twice using his leisure symbol (toy truck) during the course of the study. He did not show an increase in teacher-directed communication via his leisure symbol. Generally, Lorenzo attained scores of zero and one in this area throughout the study. He acquired more zeros (five) in this area during his last 20 intervention sessions than he did during the first 20 after baseline (one). Lorenzo did not show an increase in either spontaneous 
or spontaneously-initiated communication with his outside symbol (hip bag). He did not acquire any scores in the former area and only one in the latter. His teacherdirected communication also essentially stayed the same. His scores ranged from five scores of " 2 " during the first half of the intervention phase and four " $2 \mathrm{~s}$ " and one "3" during the second half.

Lorenzo exhibited totally spontaneous communication with his food symbol (plate) on his 13th, 29th, 35th and 38th sessions. He showed a small increase in spontaneouslyinitiated communication via his food symbol, exhibiting 3 instances of such communication during the beginning of the intervention phase, as compared to 15 occurrences during the last 20 sessions. Similarly, his teacher-directed communication via his food symbol rose from 14 instances during the first half to 43 during the second half of the intervention phase.

Lorenzo did not spontaneously communicate with his drink symbol (cup) during the study. He spontaneously initiated communication twice, once on his 26 th session and once on his $36 \mathrm{th}$. His teacher-directed communications with the cup rose from 19 during the first half of the intervention stage to 31 for the second half. Rudolfo

Rudolfo was in attendance at school for 35 out of a 


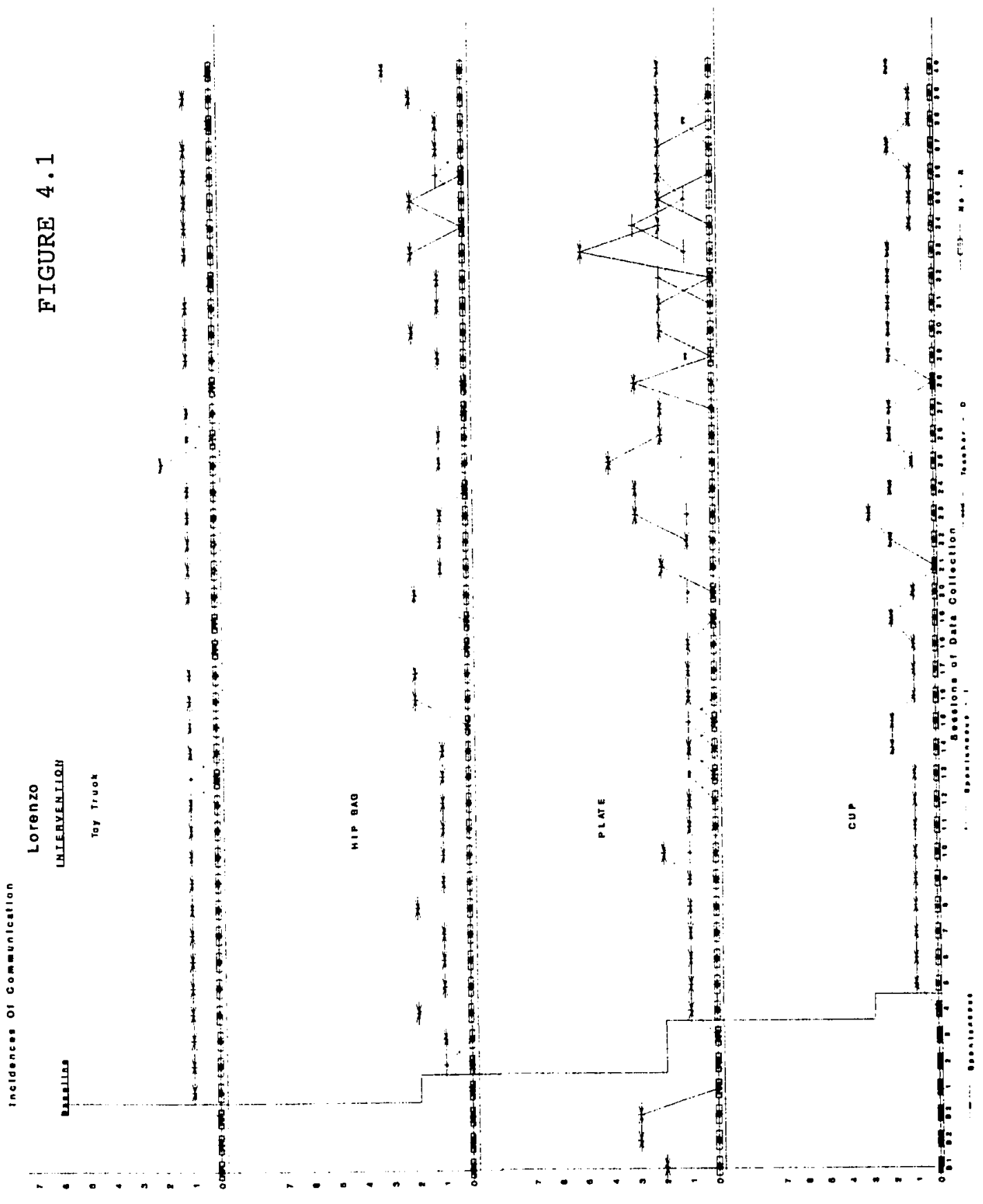


possible 50 intervention days. During six baseline sessions, Rudolfo did not communicate with total spontaneity or spontaneously initiate communication. Once intervention began, he communicated with total spontaneity 35 times and spontaneously initiated communication 76 times (see figure 4.2). Rudolfo communicated with total spontaneity once before his 26 th session. From then on, he communicated with total spontaneity every day, with scores ranging from a high of seven in one day to a low of one. Beginning with his 23 rd session, Rudolfo spontaneously initiated communication daily for the duration of the study. On 8 of his first 19 sessions, Rudolfo obtained "no response" scores ranging from one a day to a high of three a day. After his 19th session, Rudolfo's scores generally improved and he no longer obtained "no response" scores for the duration of the study. Rudolfo spontaneously communicated with his leisure symbol (block) only once throughout the study. He did not show any spontaneously-initiated communication with the block. His teacher-directed communication did not increase, as he performed from zero to two examples of this type of behavior daily throughout the study. The frequency of Rudolfo's "no response" scores with his leisure symbol decreased as the study progressed. He obtained five "no response" scores during the first 12 days of the intervention, and only one thereafter. 
Rudolfo did not exhibit any instances of spontaneous or spontaneously-initiated communication with his outside symbol (hip bag) during the intervention. His teacherdirected communication essentially stayed the same throughout the study with similar scores of zero, one and two sprinkled throughout. His frequency of "no response" scores with this symbol declined from five instances during the first 15 days to none thereafter.

Rudolfo showed an increase in spontaneous communication with his food symbol (plate). Beginning with his 26th session, his scores rose from zero to fours and fives on his 27th, 28th and 29th sessions. His spontaneously-initiated scores also increased from zero during his first 10 intervention trials, to a high of four on his 28 th session. His teacher-directed communication stayed fairly consistent, with scores of "one" "two" and 2 "zeros" throughout, and a score of three on his 27 th and 31 st sessions.

Rudolfo's spontaneous communication with his drink symbol (cup) increased as the study progressed. He did not show any spontaneous communication until his 28 th trial. From then on, he attained scores ranging from one to four. Likewise, his spontaneously-initiated communication with his cup also improved. He attained only two examples of such communication before his 22 nd session. However, from his $23 r d$ session on, he achieved scores ranging from one to a 


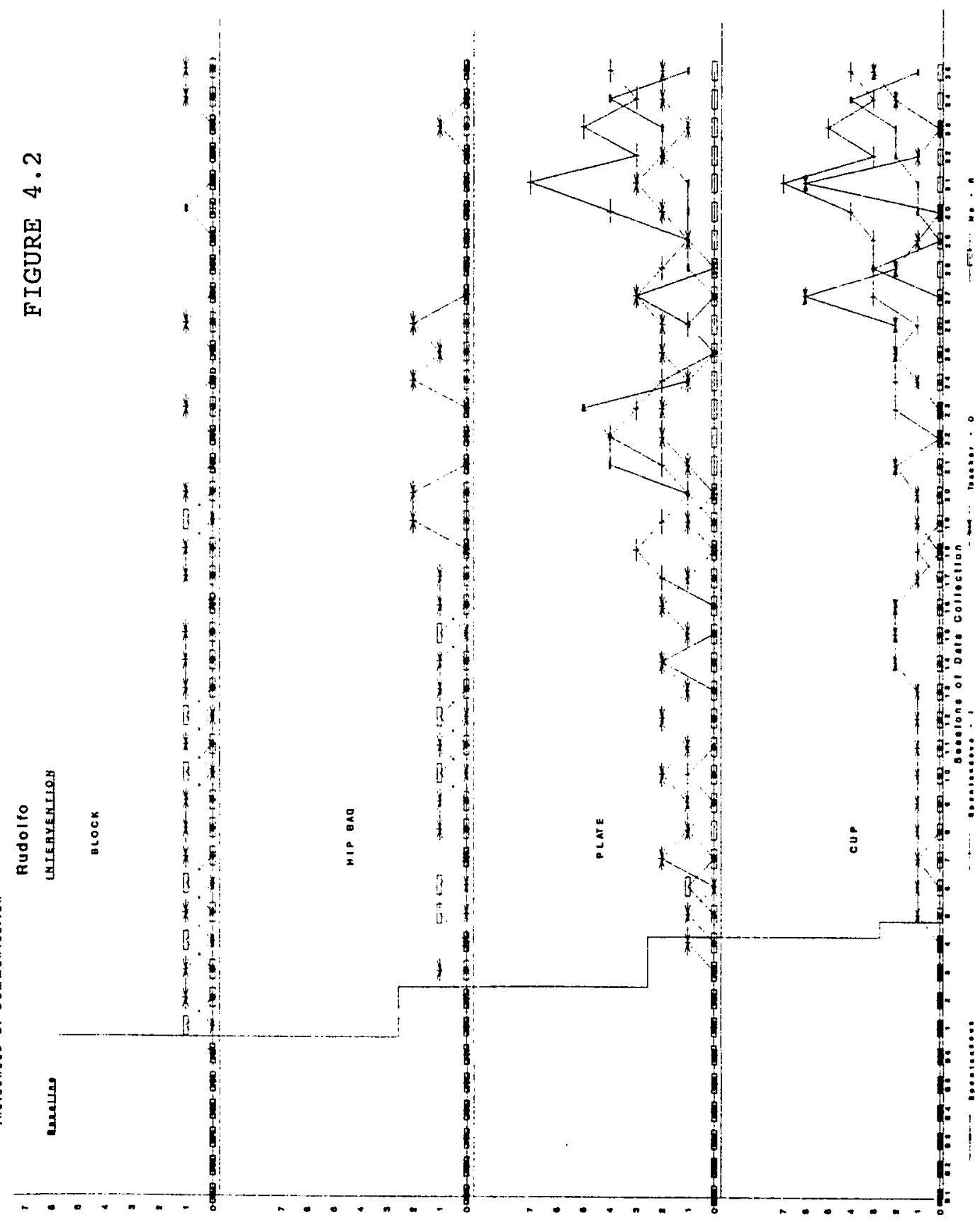


high of seven. Rudolfo's teacher-directed scores varied from one and two instances of communication to two high scores of six on his 27 th and 31 st sessions. $\underline{\text { Javier }}$

Javier was in attendance for 40 out of a possible 50 intervention sessions. While Javier did not demonstrate totally spontaneous or spontaneously-initiated communication during baseline, he exhibited a substantial increase in these skills during intervention. Over the course of the study, Javier communicated with total spontaneity 135 times and spontaneously initiated communication on 24 occasions. Javier exhibited teacher-directed communication 143 times during the research.

Javier did not evidences substantial increases in spontaneous or spontaneously-initiated communication via his leisure symbol (picture of different leisure activities). With three exceptions with the former and one with the latter, he acquired only zeros scores for these two areas throughout the study. His teacher-directed communications with the toy symbol also did not increase as a result of the intervention.

Javier exhibited substantial increases in spontaneous communications via his outside symbol (picture of school playground). While he communicated spontaneously only twice in the first half of the intervention phase of the study, he 
communicated spontaneously 47 times during the second half. Those 47 incidences can be further subdivided into 19 incidences of communication in the third quarter of the intervention stage, compared to 28 incidences during the fourth quarter. He did not evidence an increase in spontaneously-initiated communication with his outside symbol, exhibiting only three incidences in both the first and the second half of the intervention period. Similarly he did not show a substantial increase in teacher-directed communication, demonstrating only 14 such instances in the first 20 intervention sessions and 17 in the second 20 . Javier showed a substantial increase in spontaneous communication with his food symbol (picture of food). While he exhibited such behavior only 4 times during the first half of the intervention phase, he displayed it 32 times during the second half. Those 32 incidences included 6 incidences during the third quarter of this phase, compared to 26 for the fourth quarter. In contrast, Javier did not show increases in spontaneously-initiated communication, displaying this type of communication six times during the first half and eight during the second half of the intervention period. Javier's teacher-directed scores went up and down in this area. For the first quarter, he earned a score of 8; for the second quarter 15 and for both the third and the fourth quarter, scores of 7 each time. 
Throughout the study, Javier showed a substantial increase in his spontaneous communication skills with his drink symbol (picture of cup). While he did not display any spontaneous communication during the first quarter of the intervention phase, he earned a score of 6 in the second, 14 in the third and 24 in the fourth quarter. He displayed only two instances of spontaneously-initiated scores at the end of the study. Javier exhibited an increase in teacherdirected communication until the fourth quarter of the intervention condition, when his scores dipped again. Inez

Inez was present for only 25 out of a possible 51 intervention sessions. She communicated with total spontaneity 18 times and spontaneously initiated communication 13 times. She exhibited teacher-directed communication skills 92 times. Until her 22 nd session, Inez had communicated with total spontaneity only once. From then on, she spontaneously communicated daily with a high score of "10" on her last trial.

Inez spontaneously communicated with her leisure symbol (book) three times with a high score of "three" on the last day of the study. She spontaneously initiated communication seven times throughout the research, but not in an increasing trend. Similarly, her teacher-directed communication scores were either "zero" or "one" per day and 


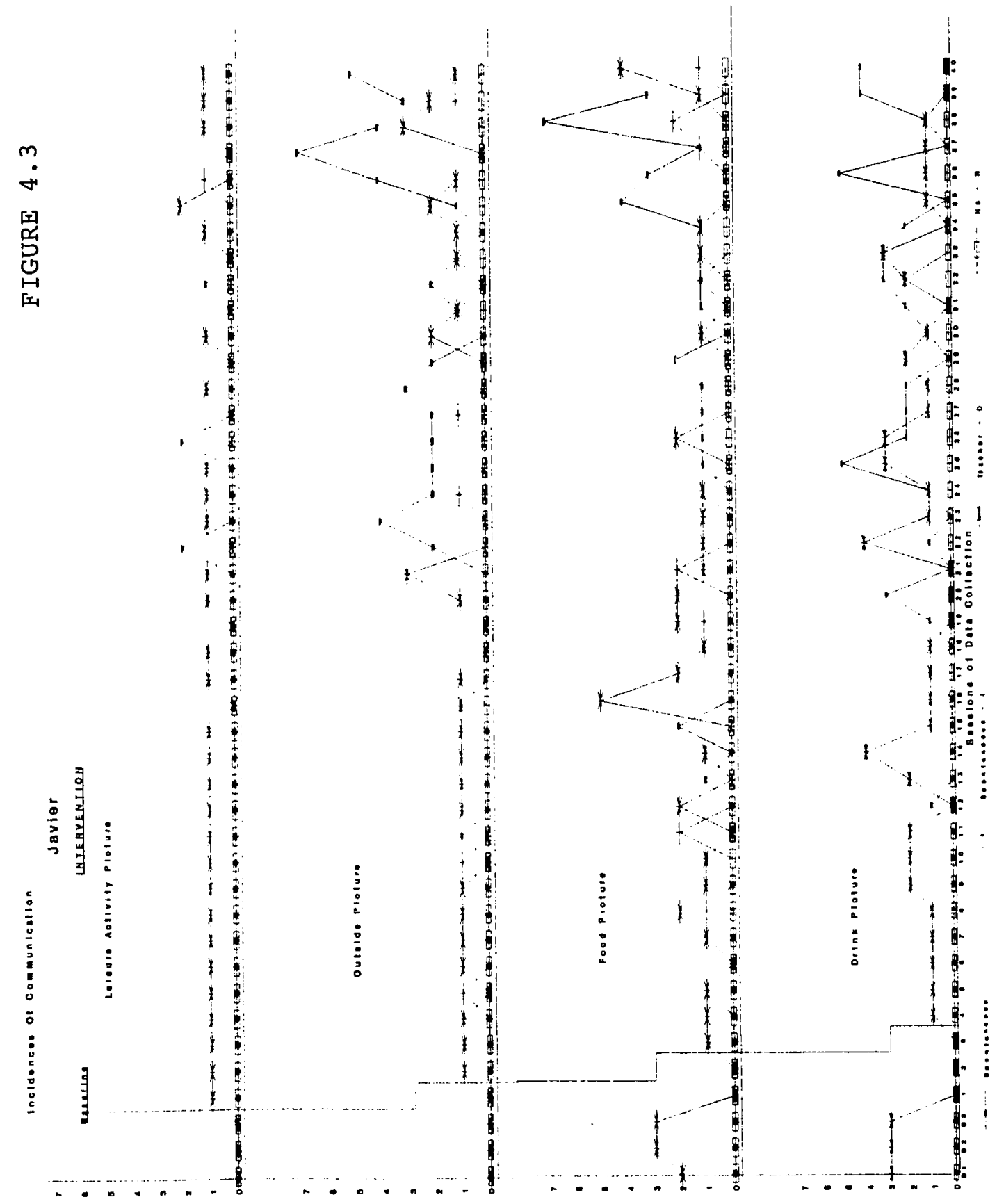


did not increase or decrease as the study progressed.

Inez did not spontaneously communicate with her outside symbol (hip bag). She spontaneously initiated communication only once with her bag. While Inez usually exhibited teacher-directed communication once or not at all with her hip bag, she attained two incidence of teacher-directed communication near the end of the study.

Inez did not display any incidences of spontaneous communication with her food symbol (plate) until her 23rd and 24 th session. On her last day of data collection, she spontaneously communicated five times. She spontaneously initiated communication on her 20 th and 24 th sessions. She began to exhibit teacher-directed communication twice a day over four days during the second half of the intervention period.

Inez spontaneously initiated communication with her drink symbol (cup) for the first time, twice a day, on the last three days of the study. She did not show any spontaneously-initiated communication except on her 13 th and 25th sessions. Her teacher-directed communication improved after her 11th session and dipped again somewhat at the end of the study as her corresponding spontaneous and spontaneously-initiated communication increased. 


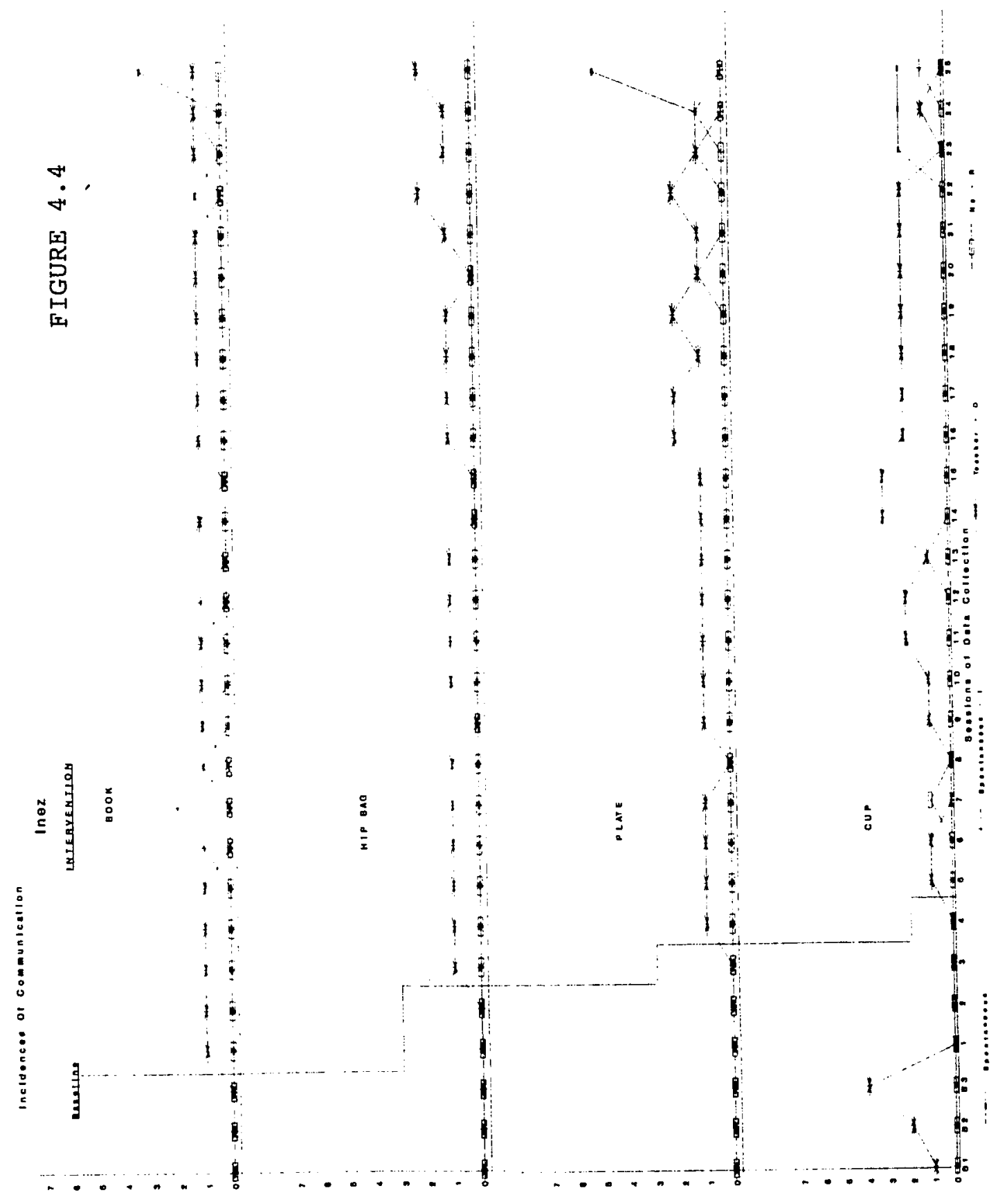




\section{CHAPTER FIVE}

\section{Discussion}

The purpose of this study was to teach students with profound disabilities to communicate basic wants and needs via their symbol shelves both spontaneously and with teacher assistance. They were instructed in four steps that made up each communicative act: walking over to their symbol shelf, selecting a symbol, displaying it to an adult and indicating comprehension of what they had communicated by going to the area of the room where the activity represented by the symbol took place. The teacher and the instructional assistant took data on both spontaneous and spontaneouslyinitiated communication (communication that is performed with total independence by the child and communication that the child spontaneously initiates, but needs help in completing). They also recorded teacher-directed communication (where the teacher directs the child toward the shelf to make wants known) and incidences of nonresponsiveness (where the child has to be directed to the shelf and needs to be physically prompted through the three subsequent steps of expressing a message).

\section{Lorenzo}

Lorenzo did not evidence a true increase in spontaneous and spontaneously-initiated communication with his leisure symbol. Several reasons for this are possible. First, he 
may not have been truly motivated by the toys selected. Even when the adult was providing Lorenzo with a lot of attention and interaction, he did not show an obvious increase in excitement when playing with his leisure materials. One sensed that Lorenzo felt one activity was as good as another if he could be near the adults. It may be indicative of a general phenomenon this researcher has seen in her class for students with profound disabilities. The pupils often don't know how to play and amuse themselves. They tend to prefer interacting with adults and peers, rather than playing with a toy. Lorenzo's teacher-directed scores may have plateaued because of constraints in the classroom schedule. Students are occupied on different tasks throughout the entire day, limiting the number of teacher-directed trials in this area.

Lorenzo's communication attempts with his outside symbol may also indicate a lack of interest in this activity. Classroom staff were surprised as he frequently seems interested in going outside, often looking out the window at other children at recess when his class was still inside. One wonders if the hip bag was too abstract a symbol for Lorenzo to comprehend. Likewise, one may have expected Lorenzo to exhibit more spontaneous or spontaneously-initiated communication with his drink symbol, as his mother reports he sometimes brings her a cup at home. 
Lorenzo's strongest communication during the study occurred with his food symbol. Perhaps this was the most concrete symbol and food the most obvious reinforcer. He likes to eat both lunch and snacks and finds edible reinforcement motivating.

Several explanations why these results were obtained with Lorenzo seem reasonable. He did not have the prerequisite gestures outlined as necessary by Rowland and Schweigert (1990). He has a passive, agreeable personality. Possibly he is not sufficiently motivated by discontent or desire to work at making wants and needs known. Lorenzo also has a tendency not to look at his shelf. He often grabs first and looks later, requiring continued instruction on focusing on relevant stimuli.

\section{Rudolfo}

Rudolfo did not show an increase in communication with his leisure symbol as the study progressed. As with Lorenzo, Rudolfo does not seem interested enough in playing with toys and different leisure materials to initiate the communication process. Similarly, Rudolfo does not evidence interest in playing outside at present, even though he had shown a preference for recess in the past.

Rudolfo's communication with his food and drink symbols improved as the study progressed. He is obviously motivated by hunger and thirst. He also appeared to be going through 
a growing phase and was very hungry and thirsty during the intervention. The concreteness of the symbols may have helped cue Rudolfo on what they represented. While one routinely uses a plate for food and a cup for drink, a hip bag and a block are more abstract symbols. It is intriguing to note in light of Rudolfo's improvement in communication, that he was the only pupil who obtained more than one score of "no response" during the intervention. While it would not have affected the course of the study, it would have been interesting to note if these scores corresponded to days Rudolfo had seizures at home.

Rudolfo's success with the two symbols may have been due to the fact he had some prerequisite gestures; a criteria emphasized by Rowland and Schweigert (1990). In the past, he would sometimes hand a cup to an adult when thirsty. Rudolfo is very slow reacting. When analyzing the results it was obvious that it took time for Rudolfo's spontaneous and spontaneously-initiated communication to develop. Ten weeks allowed Rudolfo this time. The teacher found the hierarchy of prompts a very helpful reminder for staff when working with Rudolfo. Using each level of prompting and waiting between gave Rudolfo time to react and perform without the adult rushing in and doing it for him. "Stopping and waiting" for the child to act is deemed essential by MacDonald and Gillette (1986). This restraint 
was necessary for Rudolfo to become a spontaneous communicator. Rudolfo began to see that he got what he wanted every time he communicated and was motivated to communicate again, highlighting how critical consistency is when teaching new skills. One has the impression that Rudolfo needed a certain amount of practice before he grasped the concept of expressively communicating via the symbol shelf. However, once he did, he was able to use the shelf with ease to obtain desirable items and enjoyed the expressive power he had via the shelf.

Javier

While Javier was very successful in the program as a whole, his communication skills using his leisure symbol did not increase as result of the intervention. In retrospect, it was apparent to classroom staff that too many leisure materials were available in the classroom that Javier could obtain independently. Thus he was not motivated to communicate that he wanted a toy as a need had not been created for him. Staff felt that certain materials were very motivating to Javier. After completion of the study, some of Javier's favorite toys were put in a closet so that he now has to ask to obtain them.

Javier evidenced substantial increases in his spontaneous communication skills with his food, drink, and outside symbols as the study progressed. It is apparent to 
all concerned that Javier enjoys the power communicating via the shelf has brought him. He will often bring his outside symbol to an adult soon after arriving at school so he can go outside and swing on a swing. If he sees other children outside, he will race over to his shelf and get his outside symbol with a big grin. It it interesting to note that communicating his needs often seems more important to Javier than the actual activity itself. While he often wants to go outside, he is very agreeable and cooperative about coming back inside when told, even if he has been outside for only a few minutes. This is in marked contrast to his earlier profile where he would often exhibit negative behavior when he couldn't communicate to others.

Similarly, Javier showed substantial increases in his spontaneous communication with his food symbol. He now regularly displays his food picture to an adult when he is hungry or if he sees another student eating. He also responds naturally to teacher-directed communication cues. As he communicates so spontaneously with his food symbol, his teacher-directed communication seems like an additional skill, not just a subset skill of more advanced communication. The adult can ask him if he wants food (just as one would a more verbal child) and he will communicate back very naturally using his picture. Javier also exhibited improved spontaneous communication with his drink 
symbol throughout the study and continues to do so now. While data was not collected on Javier's verbalizations, the impression of this researcher was that Javier's use of speech increased during the study. He is now saying versions of the phrase " want __ " with different nouns including the names of the four referents used in the study (toy, outside, food, drink) with less prompting than he had previously required.

While generally speaking Javier did not show substantial increases in his spontaneous-initiated and teacher-directed communication with the above symbols, that does not signify a lack of success in the program. Rather in his case, his high scores in totally spontaneous communication indicate that he bypassed these earlier steps and learned to communicate with total independence early on.

Several reasons why Javier was so successful in the program are readily apparent. First, he had all the prerequisite skills outlined by Rowland and Schweigert (1990). Second, he possesses more advanced skills than the other pupils included in the study, and it seems only logical that he will be an easier learner to teach a new communication system. He demonstrates a solid recognition of a set group of pictures and can verbally label a familiar group upon request. He has a definite set of preferred activities and was obviously motivated to communicate to 
obtain them. This is in contrast to the other students, for whom it was more challenging to find preferred activities. Since the study's conclusion, the teacher has added a fifth picture to his symbol shelf. It is a picture of a computer representing different "hit any key" computer programs that Javier enjoys operating. Classroom staff have had to spend very little instructional time showing Javier to go to his shelf and obtain his computer picture if he wants to work with the computer. The teacher and the instructional assistant feel that the symbol shelf has been a very beneficial communication tool for Javier, enabling him to spontaneously communicate his wants and needs as he so desired with ease. His shelf system has also been expanded with "auxiliary boards" detailing different choices he can make under the four general symbols contained on his initial symbol shelf array. He has truly grasped the communicative function of the shelf and as one observer noted "you can put anything on that shelf and he will understand that he can communicate with it." Inez

When analyzing the scores Inez obtained, one wishes the study had continued a little longer for her. Her high score of three incidences of spontaneous communication using her toy symbol on the last day of the study hints that she was beginning to grasp the function of her shelf and was 
enjoying the control it gave her. Her lack of spontaneous communication with her outside symbol is understandable when looking at factors occurring in the classroom. Inez has parents who are very protective and ask classroom staff to keep her inside whenever the weather is bad. As the study took place between mid November and early February, the weather was often such that Inez did not go outside to recess. Thus, she did not have as much practice with this symbol as she did with the others. In a manner similar to that described with her toy symbol, Inez began to spontaneously communicate with her food symbol at the end of the study, obtaining her high score of five in this area on the last day of data collection. Her spontaneouslyinitiated communication with her food symbol also began to develop at the end of the study. The fact that Inez spontaneously communicated with her drink symbol twice a day on the last three days of the study further supports the contention that Inez was starting to understand how to use her shelf as a vehicle for communication.

When analyzing Inez's results, the teacher and the instructional assistant felt that her poor attendance impeded her progress on the symbol shelf system. As she was only there 508 of the time during the intervention, one suspects she would have done better if she had been there more frequently. This is supported by the fact that she was 
beginning to improve at the end of the study. Her prerequisite skills were not a problem as she had the prerequisite gestures outlined by Rowland and Schweigert (1990) as critical for success. One suspects that more time and regular school attendance would have helped Inez continue this trend of rapidly increasing expressive communication skills.

\section{Limitations}

There were some limitations to the study. Initial baseline data collection (before the initiation of any part of the intervention) occurred with only two referents: food and drink. It would have been preferable to have collected baseline data on students' communicative performance with all four referents. Baseline data was not collected on the "leisure" and "outside" referents (except for one or two sessions with the outside symbol once the intervention began with the leisure symbol). Because of this, one can not state conclusively what each pupil's baseline performance was in these two areas. However, staff felt confident that each student's communication about outside and leisure activities was, at most, at the level shown during the first few initiations of the intervention. Pupils might exhibit some teacher-directed communication with the adult initiating and controlling the entire interaction. However, they did not exhibit discernable spontaneous communication 
in these areas. Also, in order to establish a stable picture of students' ability to communicate about food and drink during baseline, the instructor presented an increased number of communication trials in these areas to students. The unintended consequence was the false picture that students were exhibiting more teacher-directed communication with food and drink during baseline than they did during the initiation of the study. This impression was not created with spontaneous and spontaneously-initiated communication as pupils did not evidence these types of behaviors during baseline even with the increased number of opportunities the teacher presented to them.

\section{Research Implications}

Several implications of the results are evident. First, the use of symbol shelves with students with more involved handicaps seems validated given the success of the participants. The previous research finding that gestures are an important prerequisite for success with symbol shelves was supported by this study (Rowland \& Schweigert, 1990). Lorenzo did not truly have the gestures outlined by Rowland and he had the most difficulty of all the participants during the study. A strong desire for something also seems necessary. Lorenzo and Rudolfo did not demonstrate observable interest in their designated leisure activities. They did not appear as motivated to communicate 
about them as they were about food.

An obvious benefit of the symbol shelves was that their physical presence gave students the opportunity to communicate spontaneously. The shelves were concrete, stationary and easy for pupils to discriminate.

One anecdotal finding was the importance of stopping and waiting. As mentioned with Rudolfo, the hierarchy of prompts and the stop and wait space provided between the delivery of each prompt gave students time to respond and develop independence as MacDonald and Gillette (1986) suggested. It is recommended to try to implement systems that parents will also be able to use at home. It is important to structure for success for the parents' sake as well as the students, as it may motivate previously discouraged parents to try the shelves with their child at home.

\section{Possibilities for Further Research}

It would be interesting to see if similar results were obtained with a larger sample size. With a bigger sample group, different treatments or combinations could be tried. It would be fruitful to see if groups taught with varying amounts of redirecting did better or worse than comparison groups. Initially, during teaching, students were taught to pick each symbol at the appropriate time for the corresponding activity. As the intervention progressed it 
was difficult to know at what point to stop directing students toward a particular symbol and let them choose whatever they desired. Obviously they needed the freedom to choose in order to develop truly spontaneous, studentinitiated communication. However, some initial direction also seemed important to make sure students learned the correspondence between a particular symbol and its designated related activity, especially when the connection was not immediately apparent (e.g., outside and hip bag). While it did not necessarily change how the educator responded, questions arose as to whether to redirect a student to a different symbol when a student just "grabbed" a symbol without looking at his symbol shelf or when the adult knew the student really wanted something else (e.g., student had been trying to grab food from the lunch table. The adult directs him/her to the shelf where the student grabs the toy symbol). Future research might address the question about how long to teach the correspondence between a symbol and activity and when to begin letting a student choose whatever he so desired even if he never varied from one particular symbol.

It would be interesting to study how to better identify preferred activities with this population. Perhaps the meeting between the language and speech therapist, parents and the teacher did not provide an objective enough 
analysis. Observing a student for an entire day(s) to see what objects the learner picked up or gravitated towards might be a more behaviorally sanctioned and productive method.

It would also be illuminating to attempt a different aspect of the study or procedure. One wonders if there would be a way to perform the study with nonambulatory and/or more physically disabled students. Students in wheelchairs might need to carry their shelf with them. Blind students with profound disabilities might need to have their physical location in the classroom always planned in relation and proximity to their symbol shelf so instruction would include teaching students the mobility skills necessary to access their shelf independently.

This researcher would have liked more time for the study to see if it helped Lorenzo and Inez obtain more successful and conclusive results. It would be interesting to see if at set time increments (e.g. 10 weeks, 20 weeks, etc.) different results were realized for different samples and if, after a certain point, rates of success would level off.

The effect of the treatment by itself could have caused student improvement. Staff felt very motivated and focused on how to teach the students and what the priorities of instruction were. It would be helpful to see if similar 
results were realized with another program about which staff felt comparable excitement and motivation.

In sum, students experienced gains in their augmentative expressive communication skills after being taught how to use their individual symbol shelves. Staff felt these gains were noteworthy and validated the use of symbol shelves with this population. 


\section{CHAPTER SIX}

\section{Summary}

The purpose of this study was to determine if instruction in the use of symbol shelves helped students with profound disabilities develop improved expressive language skills. Symbol shelves can best be described as stationary object communication boards where a particular symbol represents a desirable item or activity in the environment. Three students in this research used objects as symbols and one used pictures.

Expressive language skills were divided into four types of communication. Students demonstrated spontaneous communication by communicating with total independence and without any adult prompting. They walked over to their shelf independently. Then they selected a symbol out of four choices and gave the symbol to an adult. Finally, they went to the area in the class where the activity represented by that symbol usually took place. Spontaneously-initiated communication was defined as occurring when a student walked over to the shelf without prompting, but then needed assistance in the successive steps of conveying a message. Teacher-directed communication took place when the adult directed the child to go to his/her shelf and the whole procedure was not student initiated. Finally, nonresponsiveness was coded if the child required full 
physical assistance in order to perform the four communication steps.

In general the intervention was highly successful. All four students showed some improvement in their spontaneous or spontaneously-initiated communication skills with at least one of their symbols. While Lorenzo only showed a consistent increase in his spontaneously-initiated communication with his food symbol, staff felt he was beginning to make progress in understanding what was expected of him. They found it worthwhile to continue instructing him on how to use his symbol shelf as an augmentative communication system. In addition, the three other learners demonstrated improved spontaneous communication with either two or three of their remaining symbols (Inez: book, plate and cup; Rudolfo: plate, cup; and Javier: outside picture, food picture and drink picture). While Inez's improvement really occurred during the last three days of the study, anecdotal information indicates that these improvements are long lasting. She now brings all four of her symbols to adults in gestures of evident spontaneous communication. Inez and Rudolfo also showed gains in their spontaneously-initiated communication (Inez: book and cup; Rudolfo: plate and cup). Again, though Inez's spontaneously-initiated communication occurred at the end of the study, they are behaviors she now engages in with 
increasing regularity. While Javier did not really show a dramatic increasing trend in his spontaneously-initiated communication (he had 24 incidences throughout the study), his total score pattern indicates that he basically bypassed this step and advanced directly to totally spontaneous communication.

Possibilities for further research generally include obtaining a larger knowledge base about the use of symbol shelves with students with profound disabilities. With different samples, one could examine and attempt to resolve some ambiguities of instruction that were left to instructor judgement. It would be helpful to explore how to better identify preferred activities for members of this population. As so many students in this population have multiple disabilities, relevant research for educators would include how to adapt these techniques for students who are not independently mobile. This researcher would have liked to continue the study to see if varying time intervals helped learners obtain different results. Finally, acknowledging that very focused, defined instruction tends to produce results whatever the specifics are, it would be fruitful to see if similar results were obtained with comparable programs, equally planned and developed. 


\section{References}

Adam. H. (1985, March). Ways to communicate with children who are mentally retarded and cannot speak. Paper presented at the World Congress of the International Association for the Scientific Study of Mental Deficiency, News Delhi, India.

Alberto, P. A., \& Sharpton, W. (1988). Components of instructional technology. In L. Sternberg (Ed.), Educating Students with Severe or Profound Handicaps (pp. 185-218). Rockville, MD: Aspen Publishers. Alwell, M., Hunt, P., Goetz, L., \& Sailor, W. (1989). Teaching generalized communicative behaviors with interrupted behavior chain contexts. The Journal of the Association for Persons with Severe Handicaps, 14, 91100 .

Brown, F., \& Lehr, D. H. (1989). Persons with Profound Disabilities. Baltimore, MD: Paul H. Brooks. Bryen, D. N., Goldman, A. S., \& Quinlisk-Gill, S. (1988). Sign language with students with severe/profound mental retardation: how effective is it? Education and Training in Mental Retardation, 23, 129-137.

Carlson, F. (1981). A format for selecting vocabulary for the nonspeaking child. Ianguage, Speech and Hearing Services in Schools, 12, 240-245. Downing, J. E., \& Siegel-Causey, E. (1988). Enhancing the 
nonsymbolic communicative behavior of children with multiple impairments. Language, speech and Hearing Services in Schools, 19, 338-348. Houghton, J., Bronicki, G. J., \& Guess, D. (1987). opportunities to express preferences and make choices among students with severe disabilities in classroom settings. Journal of the Association for Persons with Severe Handicaps, 12, 18-27.

Kangas, K. A., \& Lloyd, L. L. (1988). Early cognitive skills as prerequisites to augmentative and alternative communication use: what are we waiting for? Augmentative and Alternative Communication, 4, 211-221.

MacDonald, J., \& Gillette, Y. (1986). Communicating with persons with severe handicaps: roles of parents and professionals. Journal of the Association for Persons with Severe Handicaps, 11, 255-265.

Miller. J., \& Allaire, J. (1987). Augmentative communication. In M. E. Snell (Ed.), Systematic Instruction of Persons with Severe Handicaps (pp. 273296). Columbus: Charles E. Merrill.

Mirenda, P. (1985). Designing pictorial communication systems for physically able-bodied students with severe handicaps. Augmentative and Alternative Communication, $\underline{1}$, $58-64$

Mulligan Ault, M. (1988). Curriculum development. In L. 
Sternberg (Ed.), Educating Students with Severe or

Profound Disabilities (pp. 219-265). Rockville, MD: Aspen Publishers.

Rowland, C. (1985, Nov.). Concrete symbol systems: symbolic skills for children with multiple disabilities. Paper presented at the Annual Convention of the American Speech-Ianguage-Hearing Association, Washington, DC. Rowland, C., \& Schweigert, P. (1990). Tangible Symbol Systems: Symbolic Communication for Individuals with Multisensory Impairments. Tucson, AZ: Communication Skill Builders.

Siegel-Causey, E., \& Guess, D. (1989). Enhancing nonsymbolic communication interactions among learners with severe disabilities. Baltimore: Paul H. Brookes. Silverrain, A. (1982). The use of "symbol shelves" in teaching communication with multi-handicapped children. San Antonio, Texas: Education Service Center, Region 20 (ERIC Document Reproduction Service No. ED 234 594) Snell, M. E. (Ed.). (1987). Systematic Instruction of Persons with Severe Handicaps (Third Ed.). Columbus: Charles E. Merrill. Snell, M. E., \& Eichner, S. J. (1989). Integration for students with profound disabilities. In F. Brown \& D. H. Lehr (Eds.), Persons with Profound Disabilities: Issues and Practices (pp. 109-138). Baltimore, MD: Paul H. Brookes. 
Sternberg, I. (1988). An overview of educational concerns for students with severe or profound handicaps. In I. Sternberg (Ed.). Educating Students with Severe or Profound Handicaps (pp. 3-13). Rockville, MD: Aspen Publishers.

Sternberg, L. (Ed.). (1988). Educating students with severe or profound handicaps (2nd Ed.). Rockville, MD: Aspen Publishers.

Sternberg, L., \& McNernery, C. D. (1988). Prelanguage Communication Instruction. In L. Sternberg (Ed.). Educating Students with Severe or Profound Handicaps (pp. 311-363). Rockville, MD: Aspen Publishers. Sternberg, L., McNernery, C. D., \& Pegnatore, L. (1987). Developing primitive signalling behavior of students with profound mental retardation. Mental Retardation, 25, 1320 .

Thompson, B., \& Guess, D. (1989). Students who experience the most profound disabilities. In F. Brown \& D. H. Lehr (Eds.). Persons with Profound Disabilities: Issues and Practices (pp. 3-41). Baltimore, MD: Paul H. Brookes. Wacker, D. P., Wiggins, B., Fowler, M., \& Berg, W. K. (1988) Training students with profound or multiple handicaps to make requests via microswitches. Journal of Applied Behavioral Analysis, 21, 331-343. 


\section{Appendix A}

October, 1990

Dear

Over the past six years, my goals for our classroom have included improving the communication skills of all my students. This year communication skills will be emphasized even more in our daily classroom schedule. In addition to being your child's teacher, I am presently a graduate student at San Jose State University. I am pursuing a Master of Arts degree in Education. This year I will be working on my master's thesis. For my thesis, I will be doing a research study with four of my students. I will be attempting to teach them how to communicate to others through an augmentative communication system. I want to see if instruction in this augmentative communication system will help the children communicate more spontaneously. They will be taught to use symbol shelves to communicate as a substitute for verbal language. Symbol shelves can best be described as stationary communication boards. They may contain objects as symbols that represent something else (e.g., your child may learn that an actual ball represents recess and be taught to bring an adult that ball when s/he wants to go to recess). They may also contain pictures (e.g., the child may be taught to bring an adult the picture 
of "outside" to show $s /$ he wants to go to recess). I am very excited about this project and feel it will be very beneficial to your child.

With your permission, I would like your child to participate in my study. Instruction in the use of symbol shelves will continue for ten weeks. Before beginning the study, the language and speech therapist, you and I will need to meet together to discuss what symbols to include in your child's symbol shelf. The symbols need to be meaningful and useful for your child (e.g., we would not choose a symbol for "book" if your child is not interested in books). We will also meet together in order for me to describe the study in more detail. When my study is completed, if we feel symbol shelves have been helpful for your child and you so desire, we can meet together and help you implement a symbol shelf system at home.

If you do agree to let your child participate in this study, please fill out the enclosed form. Feel free to call me at school (phone \#___ ) if you have any questions. Thank you for your assistance.

Sincerely,

Gail stewart

Special Day Class Teacher 


\section{Appendix B}

Agreement to Participate in Research

San Jose State University

Responsible Investigator: Gail Stewart

Type of Protocol: Developing an augmentative communication system for students with profound disabilities.

Your child is invited to participate in a research study that is exploring how to promote spontaneous and teacherdirected expressive communication in children with severe/profound disabilities. The results of the study should further our understanding about whether symbol shelves are an effective communication device for this population.

I understand that:

1) I will be asked to let my child participate in this study for ten weeks during his regular classroom day. Prior to the initiation of the study, I will meet with the teacher and language and speech therapist to choose appropriate augmentative communication symbols for my child. 2) The possible benefits of this study to my child are that s/he will show growth in communicating basic wants and needs to others.

3. The results from this study may be published, but any information from this study that can be identified with my 
child will remain confidential and will be disclosed only with my permission.

4) Any questions about my child's participation in this study will be answered by Gail stewart (phone \#:____ Complaints about the procedures may be presented to Dr. Susan Pellegrini (phone \#__ ) For questions and complaints about research subject's rights, or in the event of research-related injury, contact serena stanford, Ph.D. (Associate Academic Vice President for Graduate Studies and Research) at

5) My consent is given voluntarily without being coerced; my child may refuse to participate in this study or in any part of this study, and I may withdraw my consent at any time, without prejudice to my relation or my child's with San Jose State University.

6) I have received a copy of this consent for my file.

HAVING READ THE INFORMATION PROVIDED ABOVE, I HAVE MADE A DECISION WHETHER OF NOT MY CHILD MAY PARTICIPATE. MY SIGNATURE INDICATES THAT MY CHILD MAY PARTICIPATE AND IS WILLING TO PARTICIPATE.

$\overline{\text { DATE }} \overline{\text { PARENT'S/SIGNATURE }} \overline{\text { CHILD'S NAME }}$


Appendix C

Format 1: Environmental Inventory

Child: Date: Cataloger(s):

\begin{tabular}{llll}
$\begin{array}{c}\text { Time } \\
\text { length }\end{array}$ & Setting Area & $\begin{array}{l}\text { Participatory } \\
\text { Activities }\end{array}$ & $\begin{array}{r}\text { Observed } \\
\text { Activities }\end{array}$ \\
\hline
\end{tabular}

Format 2: Vocabulary List

Area : Date: Cataloger(s):

Categories People Actions Places Feelings Silly Words Concepts or Words

\footnotetext{
* Concepts within the child's experience

\#Concepts at the child's developmental level

+Concepts of interest to the child

Carlson, F. (1981). A format for selecting vocabulary for the nonspeaking child. Language, Speech and Hearing Services in Schools, 12, 240-245.
} 
Appendix D

Symbol Data Sheet Training Sessions/Student Initiations student: Date: Instructor:

Symbol

Time

1. ACCESS SYMBOL array Cue:

Response:

2. SELECT SYMBOL

Cue:

Response:

3. DISPLAY SYMBOL

Cue:

Response:

4. COMPREHEND SYMBOL Cue:

Response:

\section{Spontaneous:}

Spont. Initiated:

Teacher Directed:

No Response:

PROMPT CODE :
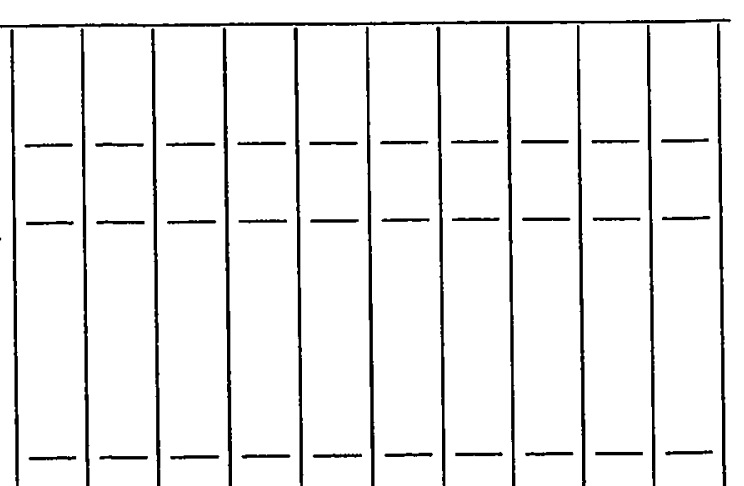

+: Performed step independently

-: Did not perform step independently

If -, also note level of prompting required to complete

step: $\mathrm{V}=$ verbal, $\mathrm{G}=$ gesture, $\mathrm{PP}=$ partial physical assistance, FP = Full Physical Assistance

Adapted from Rowland, C. \& Schweigert, P. (1990). Tangible symbol Systems: Symbolic Communication for Individuals with Multisensory Impairments. Tucson, AZ. Communication Skill Builders. 